\title{
COMUNICACIÓN Y NEGOCIACIÓN EN BABEL, DE ALEJANDRO GONZÁLEZ IÑÁRRITU
}

\section{Graciela Padilla Castillo}

Universidad Complutense de Madrid. Departamento de Periodismo III, Madrid, España.

Resumen

La presente investigación analiza la película Babel (2006), dirigida por el mexicano Alejandro González Iñárritu. Su tercera obra indaga en la comunicación intrapersonal e interpersonal del ser humano, a través de todo lo que se dice y lo que no se dice. Más allá de la perfección estética o cinematográfica, se analizan diversas teorías de la comunicación y la negociación, que aparecen y destacan sobremanera en el metraje. La hipótesis de la que se parte es que la grandeza y calidad de Babel no está sólo en su montaje, paisajes, música original o interpretaciones de los actores, sino en la profundidad del mensaje que quiere transmitir. Los personajes apenas hablan y la película tiene muchos momentos de silencio. Sin embargo, sus breves líneas de diálogo, unidas a sus gestos y movimientos, están plagadas de ejemplos comunicativos dignos de ser examinados.

Palabras clave:

Alejandro González Iñárritu, Babel, Estilos de comportamiento, Aristóteles, John Stuart Mill, Ventana de Johari, Abraham Maslow, Negociación.

\section{INTRODUCCIÓN}

Alejandro González Iñárritu se ha convertido en uno de los directores más influyentes y respetados de la actualidad, gracias a sus tres únicas películas. El director mexicano se dio a conocer con Amores Perros. Entró en el Hollywood con 21 gramos y ha confirmado su talento con Babel. Según sus propias palabras, ha cerrado su trilogía sobre la incomunicación del ser humano y por ello, sus trabajos merecen ser analizados desde las teorías de comunicación interpersonal.

Esta investigación se centrará en la última película, Babel, la más compleja del grupo y mejor valorada por la crítica. Su título alude a la historia bíblica de la Torre de Babel, narrada en el libro del Génesis. Los hombres la construyeron para intentar alcanzar el cielo. Yahvé quiso evitarlo e hizo que hablaran distintas lenguas, lo que llevó al caos y a la dispersión de todos ellos por todo el mundo. González Iñárritu aprovecha esa expansión mundial para proponer un viaje por cuatro países distintos (Estados Unidos, México, Marruecos, Japón) y retratar, en la actualidad, la anarquía e incomunicación que predecía el relato bíblico. 
Sin embargo, este estudio no se centrará en el juicio crítico, estético o cinematográfico de la película. El objetivo es estudiar su guión y diálogos, con ejemplos concretos, para ver en ellos los estilos de comportamiento de cada personaje y otros importantes juegos de comunicación, que utilizan para sobrevivir. La hipótesis de la que se parte es que la grandeza y calidad de Babel no está sólo en su montaje, paisajes, música original o interpretaciones de los actores, sino en la profundidad del mensaje que quiere transmitir. Los personajes apenas hablan y la película tiene muchos momentos de silencio. Sin embargo, sus breves líneas de diálogo, unidas a sus gestos y movimientos, están plagadas de ejemplos comunicativos dignos de ser examinados.

\section{ARGUMENTO}

Abdullah, un pastor de Marruecos, compra un fusil Winchester para que sus hijos puedan espantar a los lobos y así mantener a salvo las ovejas de su rebaño. El más pequeño, Yussef, es un gran tirador y quiere demostrárselo a su hermano. El blanco de la prueba es un autobús blanco que circula a lo lejos, por un camino solitario, en medio del desierto. La bala inocente llega al hombro de Susan, una turista norteamericana que duerme en el asiento del vehículo. Su marido, Richard, ha planeado el viaje a Marruecos para que puedan estar solos y arreglar su matrimonio roto. Perdieron un niño y él huyó, algo que Susan no puede perdonarle.

En su casa de San Diego les esperan Mike y Debbie, sus otros dos hijos. Les cuida Amelia, una mujer mexicana, aunque plenamente asentada en los Estados Unidos. Vivió la muerte del pequeño Sam y ha criado a los otros dos niños con mucho esmero. Sin embargo, su único hijo se casa en el Valle de Guadalupe y sólo desea encontrar una canguro que pueda sustituirle en ausencia de los padres. El último recurso será llevar a los pequeños con ella a México, algo que tendrá fatales consecuencias.

El otro vértice de esta gran historia se desarrolla en Japón. Allí vive Yasujiro, un ejecutivo acomodado y aficionado a la cacería exótica. Uno de sus viajes le llevó a Marruecos, donde regaló su Winchester al que fue su guía, Hassan, vecino y amigo de Abdullah. Pero Yasujiro ya no recuerda aquellos tiempos felices. Su mujer se suicidó en presencia de su hija, Chieko, una adolescente sordomuda y deprimida por sus recuerdos y su minusvalía. La relación paterno-filial está muy degradada y ambos no encuentran consuelo para seguir adelante.

Cuatro países. Cuatro historias entrecruzadas, unidas por un fusil que es el detonante para cuatro desgracias casi paralelas. Todos los protagonistas sufren por lo que no dicen. La casualidad les pondrá a prueba para poder expresar todo lo que han callado y seguir adelante con una vida nueva.

\section{ESTILOS DE COMPORTAMIENTO}

REFLEXIVO: Richard es un personaje absolutamente reflexivo. Tiene el afecto bajo y el poder bajo. Después de la muerte de su hijo, simplemente huyó porque tenía miedo. Su actitud es cobarde y sigue reprochándose su actuación. Tampoco tiene 
valor para hablar con su mujer, Susan, y explicarle por qué huyó. Sigue queriéndola, pero tiene miedo a sus reprimendas y prefiere guardárselo en su mundo propio, aislado de la familia que formó hace años.

El viaje a Marruecos es su última oportunidad. Lo preparó para reflexionar y ordenar su vida con Susan. Necesita hablar del pasado, de la muerte de su hijo Sam, para ver cómo ha influido en su presente como pareja. Pero no sabe cómo afrontar la situación y tiene muchas dificultades para comunicarse.

Chieko también tiene un comportamiento reflexivo. Es sordomuda y vio a su madre suicidarse ante sus ojos. Esos dos hechos la llenan de tristeza y marcan todos los momentos de su vida: el partido de voleibol, la reunión con sus amigas, la visita al dentista o su primer encuentro sexual con el teniente de policía. El pasado marca su presente y llora porque imagina un futuro de tristeza e incomprensión.

PERCEPTIVO: Yasujiro es un tipo perceptivo. Ha aceptado el suicidio de su esposa después de nueve meses de tristeza e interrogatorios con la policía. Rememora esos recuerdos cada día, pero quiere salir adelante y ayudar a su hija. Es una persona sensible y le duele mucho la mala relación que mantiene con Chieko. No obstante, se ha adaptado a esa situación y espera resolverla. Tiene el poder bajo. No sabe tomar decisiones y cree que ya no puede educar a la adolescente. No tiene fuerza para hablar con ella, ni siquiera para regañarla y ayudarla a sacar el dolor que los dos llevan dentro.

INTUITIVO: Los personajes de Susan y Amelia tienen comportamientos intuitivos. La primera ha sufrido la muerte de un hijo y se culpa por ello, ya que cree que fue fruto de su descuido. Después del fatal suceso, vivió otra tragedia: Richard les abandonó. Aunque Susan supo salir adelante, orientarse hacia el futuro y preocuparse de los dos hijos que le quedan. Ellos y su propia vida son su fuerza y cree que puede seguir adelante sola sin su marido, al que no puede perdonar. Por otra parte, Amelia salió de México para labrarse una vida mejor. Trabaja en Estados Unidos, con una buena familia que confía en ella y envía el dinero que gana a sus hijos. Es una luchadora y sigue adelante con su trabajo. Mueve su propio mundo y su única preocupación son los niños. Cuando los pierde en el desierto y es detenida, no le importa qué será de ella; sólo quiere encontrarlos sanos y salvos.

DINÁMICO: Santiago, sobrino de Amelia, es el personaje que reúne las características dinámicas. Quiere mucho a su tía, pero es un joven juerguista, bebedor e irresponsable. Su objetivo es divertirse en el presente. No se le conocen trabajo ni responsabilidades; sólo desea explayarse en la boda de su primo. Cuando le para el agente de la aduana y ve posibles problemas, toma la decisión inmediata de huir. No piensa en el peligro que corren los niños. Sólo quiere evitar ser detenido por conducir ebrio y no dedica ni un segundo a la reflexión. Pisa el acelerador y conduce a toda velocidad. Cuando despista a la policía, detiene el coche de repente y no duda en echar a su tía Amelia y a los niños fuera del coche, para dejarles en pleno desierto. 


\section{RECONOCIMIENTOS DE ARISTÓTELES Y CÁNONES DE CAUSALIDAD DE JOHN STUART MILL}

Babel tiene una duración de 143 minutos. Durante este tiempo, los personajes intercambian muy pocas palabras. De hecho, todos los diálogos, a excepción de pocas líneas en las que no se encontró relevancia, están recogidos en este análisis. Por ello, resulta complicado encontrar reconocimientos. Sin embargo, el espectador puede ayudarse con las interpretaciones de los actores. Sus gestos, sentimientos y movimientos transmiten mucho más de lo poco que dicen con sus palabras. A este respecto, cabe recordar una afirmación de Eric Berne (2007: 29):

La observación de cualquier actividad social espontánea, realizada de una forma muy productiva en determinados tipos de grupos de psicoterapia, revela que, de vez en cuando, las personas manifiestan unos cambios notables en su postura, punto de vista, tono de voz, vocabulario y otros aspectos conductuales. Estos cambios de conducta suelen ir acompañados de alteraciones en los sentimientos.

Ya en la película, podemos encontrar reconocimientos por indicios. Los policías marroquíes ven la foto de Hassan con Yasujiro, en medio del desierto, después de cazar un gran lobo. El japonés sostiene el rifle con el que, un año después, alguien ha disparado a Susan. Por ello, la fotografía sustenta la coartada de Hassan, que se pronuncia inocente al haber vendido el arma a Abdullah:

Hassan: Les digo que un cazador me lo vendió.

Policía: ¿Qué cazador?

Hassan: Un cazador japonés me lo dio. Tengo una foto, si quiere verla. Ella la puede traer.

Policía: Vaya a por esa foto.

(Su mujer, esposada, va a por la fotografía acompañada por un policía y vuelve con ella)

Policía: Siéntate.

Hassan: Tiene en la mano el fusil que me dio.

Los verdaderos culpables del disparo han sido Yussef y Ahmed, dos niños ingenuos y despistados que competían para saber quién dispara mejor. Después de que la bala de Yussef alcanzara el autobús, los críos ven que el vehículo se detiene y huyen asustados. No saben qué ha pasado realmente. Pero vuelven a su casa y se encierran en una habitación oscura. Su madre ha visto que las ovejas están solas en el campo y les regaña porque no han terminado su trabajo. Como excusa, los pequeños utilizan un paralogismo y se inventan un fortuito dolor de estómago:

Madre: ¿Qué hacéis aquí?

Ahmed: Algo nos ha revuelto el estómago.

Madre: Las cabras se están muriendo de hambre. Lavaos y sacad las cabras a pastar.

Ahmed: Me duele el estómago.

Madre: Tenéis muchas cosas que hacer. Fuera de aquí. Largaos.

(Zorah y Yussef se miran. Obedecen a la madre y salen de la habitación) 
Finalmente, los niños no aguantan más la mentira que están ocultando. Saben que la policía está buscando a su padre y quieren decirle la verdad. Ellos llevaban el rifle y Yussef fue el que disparó al autobús de turistas. Revelan su crimen a través de una declaración y Ahmed lo aprovecha para decir a su padre que Yussef observa a Zorah cuando se desnuda, con el consentimiento de ella:

Ahmed: Papá, papá. La policía te está buscando.

Abdullah: ¿A mí? ¿Por qué?

Yussef: No, a ti no. Nos busca a nosotros.

Abdullah: ¿A vosotros? ¿Por qué?

Yussef: Por la turista.

Abdullah: ¿Qué turista?

Ahmed: La americana. Yussef la mató.

Yussef: Fuimos los dos.

Abdullah: ¿Cómo?

Madre: ¿Pero qué estáis diciendo?

Ahmed: Yussef empezó a disparar a los coches, para ver si llegaban las balas.

Yussef: Tú les empezaste a disparar.

Ahmed: ¡Pero tú la mataste!

Abdullah: ¿Pero de qué habláis?

Ahmed: Yussef mató a la americana y espía a Zorah desnuda. ¡Y Zorah le deja!

Zorah: Es mentira, papá. Te lo aseguro.

Ahmed: ¡No es mentira! Ella es una puta y él la espía.

(Los niños se pegan y el padre intenta separarles)

Cuando la historia se traslada a Japón, la amiga de Chieko sabe que la policía ha estado en su casa, gracias a una tarjeta de visita del teniente, que está sobre el aparador de la entrada y funciona como indicio:

Amiga de Chieko: ¿Vinieron de nuevo los policías?

Chieko: Sí, no habían venido en nueve meses. Pero estos fueron policías diferentes.

Amiga de Chieko: ¿Vinieron a preguntar sobre la muerte de tu madre?

Chieko: No, pero probablemente le preguntarán a mi papá sobre lo mismo.

Amiga de Chieko: ¿No son muy convincentes o sí?

Chieko: Lo creas o no, uno de ellos me gustó.

(Se ríen las dos a plena carcajada)

Amiga de Chieko: Idiota. ¿Te pusiste pantys?

(Chieko se sube la falda y vuelve a estar sin ropa interior. Su amiga se ríe y se levanta la suya para mostrarle que ella también se ha quitado las bragas)

Por otra parte, el fusil Winchester es el objeto que une las cuatro historias. La bala que alcanza a Susan es disparada por Yussef, cuyo padre se la compró a Hassan, que a su vez trabajó como guía para Yasujiro. El espectador desconoce esta conexión hasta la parte final de la película, cuando el japonés reconoce que fue un regalo y no un arma comprada en el mercado negro. Se establece así un canon de 
concordancias, ya que cuatro hechos tienen en común el fusil, que es el efecto de los cuatro fenómenos:

Teniente: Buenas noches, soy el teniente Mahmiya.

Yasujiro: Bien, ¿en qué puedo ayudarle?

Teniente: Quería hablarle de un suceso. Siento molestarle, pero tenía que hacerle una pregunta. ¿Tiene usted un Winchester calibre 270, número de serie UK9023?

Yasujiro: No recuerdo el número. Pero hace tiempo tuve un fusil de ese modelo.

Teniente: ¿Es cierto que se lo regaló a un marroquí llamado Hassan lbrahim? Yasujiro: ¿Hassan Ibrahim?

Teniente: Ese hombre ha dicho que fue su guía en una cacería, ¿es verdad?

Yasujiro: Oh, sí. Claro, ya caigo. Ahora le recuerdo. Fue un buen guía. Se portó tan bien que se lo regalé al irme. ¿Ha ocurrido algo?

Teniente: Verá, ese fusil fue usado en un intento de asesinato y la policía marroquí quiere confirmar que el arma no fue adquirida en el mercado negro.

Yasujiro: Oh, no. Eso es imposible, porque se lo regalé yo. ¿Cómo está Hassan? ¿Se encuentra bien?

Teniente: Lo siento, no lo sé.

Yasujiro: ¿Está aquí porque estoy implicado en un delito?

Teniente: Por ahora no se trata de eso. ¿Pero podría pasar mañana por la comisaría? Tenemos que hacerle unas preguntas.

Yasujiro: Estaré allí.

Este diálogo termina con unas líneas finales cargadas de dramatismo, ya que se acerca el final de la película. Chieko le ha dicho al teniente que su madre se suicidó tirándose por el balcón. Pero al hablar con el padre de la joven, el policía descubre por una declaración de Yasujiro que el suicidio no fue de ese modo:

Teniente: Bien. Disculpe, señor. Quería decirle otra cosa. Su hija me ha contado lo que le pasó a su mujer desde su balcón. Lo siento mucho.

Yasujiro: ¿Qué balcón?

Teniente: Me ha dicho que su mujer se arrojó al vacío desde el balcón de su casa.

Yasujiro: Eso no fue así. Mi mujer no se tiró. Se pegó un tiro en la cabeza. Mi hija fue quien la encontró. Se lo he explicado mil veces a la policía. Ya estoy harto de oírlo.

Teniente: Lo siento. Le prometo que no le molestaremos más. Buenas noches.

Si se va más allá, se puede afirmar que toda la película contiene un gran canon de variaciones concomitantes. Las cuatro tragedias personales ocurren como resultado de alguna de las otras, a pesar de la distancia espacial. Una situación varía cuando otra situación cambia en otro punto. Yasujiro vende el arma - Yussef tiene un fusil con el que disparar - Susan resulta herida - Richard ve la muerte de cerca y no denuncia a Amelia, a pesar de haberse llevado a sus hijos a México, sin su consentimiento. 


\section{LA VENTANA DE JOHARI}

Los personajes de Babel destacan por sus dificultades de comunicación con las personas que les rodean. Tienen secretos, dolores y complejos muy profundos que intentan ocultar. Sin embargo, distintos sucesos les llevarán a cambiar su postura y a compartir todo lo que guardaban. Por ello, en la película hay muchos cuadrantes de la Ventana de Johari que cambian y se mueven hacia un lado u otro, según el momento.

El C1 o Cuadrante Abierto es lo que sé yo y saben los demás. Hay pocos cuadrantes de este tipo en la película. Pero uno de ellos se encuentra en una conversación entre Amelia y Debbie. La niña es consciente de la muerte de su hermano Sam, aunque aún es muy pequeña. Tiene miedo a la oscuridad, porque su hermano murió mientras dormía, y le manifiesta a Amelia esta inquietud abiertamente:

Debbie: Amelia, Amelia, ¿puedes dejar la luz encendida?

Amelia: Pues si ya están durmiendo juntos... ¿No quedamos que se iban a dormir con la luz apagada?

Debbie: Tengo miedo.

Amelia: No pasa nada, mi hijita.

Debbie: Pero tengo miedo de que me pase lo mismo que a Sam.

Amelia: Ay, mi hijita. Eso no te va a pasar a ti. No te va a pasar.

Debbie: Pero Sam se murió mientras dormía.

Amelia: No, eso sólo les pasa a los niños que son muy chiquitos. Tú hermano está arriba en el cielo. Me quedaré con ustedes, pero sin hablar. A dormir...

(Amelia acaricia a Debbie hasta que se duerme)

En segundo lugar, se encuentra el $\mathbf{C 2}$ o Cuadrante Ciego, que se refiere a lo que saben los demás, pero es desconocido para mí. Como ejemplo, Babel propone la venta del fusil entre Hassan y Abdullah. El primero oculta que es un arma usada, antes propiedad de un japonés. Su mujer le ayuda, ya que también está presente y para Abdullah, es una información desconocida. El matrimonio esconde la procedencia para ganar dinero en el negocio:

Abdullah: Está casi nuevo.

Hassan: 300 balas, mira. El tipo que me lo dio me dijo que tenía un alcance de 3 kilómetros.

Abdullah: ¿Cuánto pides por todo?

Hassan: 1.000 dirhams.

Abdullah: ¿1.000 dirhams? Te doy 500 y un cabrito.

(Ambos ríen y cierran el trato)

Sin embargo, se pueden obtener ejemplos más claros de este cuadrante ciego en las conversaciones que tienen lugar en la aldea marroquí. Susan está herida y la llevan al pueblo de Anwar, el guía turístico. Él habla en árabe con el veterinario, que hace de médico, y Richard se pone nervioso porque ellos saben cómo está Susan y él no les entiende. La información es desconocida para este personaje y está en el cuadrante ciego hasta que Anwar se lo traduce y pasa al cuadrante abierto: 
Médico de aldea: (En árabe) La bala no tocó su espina. Si se queda así, se desangrará hasta morir.

Richard: ¿Qué ha dicho?

Anwar: Dice que se pondrá bien.

Richard: Joder, no me mientas. Dime lo que ha dicho. Vamos, dime lo que ha dicho.

Médico de aldea: (En inglés) Hospital.

Richard: Ya sé que tiene que ir a un hospital.

Médico de aldea: (En árabe) Tengo que coser la herida para que deje de sangrar.

Anwar: Necesita coser la herida.

Susan: ¿Qué ha dicho?

Richard: Dice que necesitas puntos, cielo.

Susan: ¿Puntos dónde? ¿Qué tipo de puntos?

Richard: ¿Qué tipo de médico es?

Anwar: Es veterinario.

Médico de aldea: (En árabe) Y dígale que su clavícula está rota.

Anwar: Dice que tiene un hueso roto y hay que inmovilizarlo. Si no le cose la herida, morirá desangrada.

(El médico quema la aguja para desinfectarla)

Susan: Richard, no quiero que me cosan. ¡Richard!

Médico de aldea: (En árabe) Tenemos que mantenerla abajo.

Richard: Espere, espere, espere, espere.

Susan: Richard.

Richard: No aguantarás mucho si no paramos la hemorragia.

Susan: Richard, no.

Richard: Espere. Tienes que ser fuerte. Tienes que ser fuerte.

Más adelante, Susan empeora. El veterinario ha cosido su herida, pero no ha podido sacar la bala. La hemorragia ha cesado, pero ella se acerca a la muerte. Richard está muy nervioso porque no llega la ambulancia prometida. Un militar marroquí se ha trasladado hasta el lugar para decir que no habrá ninguna ambulancia, porque la embajada americana quiere mandar un helicóptero que no llega. En ese momento, vuelve a producirse una situación similar a la descrita en el diálogo anterior. Richard no entiende el árabe y desconoce lo que saben Anwar y el militar:

Richard: ¡Vamos, busque otra ambulancia! ¡Haga algo!

Anwar: ¿Por qué no puedes llamar otra ambulancia?

Militar: (En árabe) Me acaban de avisar que la ambulancia no vendrá. Y tú sabes que no hay otra ambulancia.

Anwar: No hay otra ambulancia.

Richard: ¿Cómo que no hay otra ambulancia? Haga algo, joder. ¡Vamos, búsqueme otra ambulancia!

Anwar: Él quiere saber cómo sacar a su esposa de aquí.

Militar: (En árabe) Dile que su embajada dijo que se haría cargo.

Anwar: Su embajada se encargará.

Richard: ¿Cómo que mi embajada? Estamos en su maldito país. Es su responsabilidad. ¡Haga algo! 
Militar: (En árabe) Los americanos detuvieron la ambulancia. Querían enviar un helicóptero pero hubo problemas.

Anwar: Dice que fue su embajada la que paró la ambulancia. Enviarán un helicóptero.

Richard: ¿Tengo que esperar al helicóptero? ¡Haga algo! ¡Joder!

En tercer lugar, se halla el C3 o Cuadrante Oculto, que concierne a lo que sé yo y los demás no saben. El primer ejemplo se encuentra en una discusión entre Ahmed y Yussef. El primero sabe que el segundo observa a la hermana de ambos, Zorah, mientras se desnuda, con el consentimiento de ésta. Los dos culpables no lo saben, pero Ahmed lo desvela y pasa del C3 al C1 en esta conversación:

Yussef: A Zorah no le molesta.

Ahmed: A ella no, pero a mí, sí.

Yussef: Esto sólo es entre ella y yo.

Ahmed: Los dos sois unos cerdos. La próxima vez, se lo digo a papá.

Yussef: Cállate, tú no te metas.

Ahmed: Si no quieres que me meta, no lo hagas.

Otro ejemplo relevante se encuentra también en la historia que se desarrolla en Marruecos. La familia de pastores está cenando cuscus y el padre relata inocentemente que ha llegado tarde porque una turista americana ha sido asesinada en la carretera. Es una información que su familia desconoce, porque no han salido de la casa. Al contarlo, pasa a formar parte del C1 y los niños empiezan a asustarse. Además, éstos también están en el C3 al ocultar a su padre que ellos han sido los verdaderos culpables:

Abdullah (padre de los niños): ¿Habéis matado algún chacal?

Yussef: Les disparamos, pero no le dimos a ninguno.

Abdullah: Si no le matáis, se comerá las cabras.

Madre: ¿Por qué has llegado tan tarde?

Abdullah: Han cortado la carretera y hemos dado un rodeo. Parece que unos terroristas han matado a una turista americana.

Madre: ¿Una americana?

Abdullah: Sí. Han atacado un autobús de turistas.

Yussef: Es raro. Por aquí no hay terroristas.

Abdullah: Nunca se sabe.

Yussef: ¿Cómo sabes que se ha muerto?

Abdullah: Eso han dicho. La policía está buscando a los culpables.

(Los hermanos se miran con complicidad y se sienten culpables)

El último lugar lo ocupa el C4 o Cuadrante Desconocido: Lo que no sé yo, ni saben los demás. Como muestra, Babel ofrece la escena en la que Hassan es interrogado por la policía. Ni él, ni el agente saben quién ha sido el artífice del disparo que ha alcanzado a Susan. El policía se muestra violento porque tiene claro que el anciano es culpable. Mientras, Hassan se muestra sorprendido y nervioso porque no sabe de qué disparo le están hablando:

Esposa de Hassan: (Asustada) Hassan, ¿has quedado con alguien? 
Policía: ¿Hassan Ibrahim?

Hassan: Sí

Policía: ¿Vas armado?

Hassan: No tengo armas.

Policía: Tira el arma (Refiriéndose al cuchillo con el que estaba preparando la cena) Suéltalo. He dicho que lo sueltes. Tírate al suelo. Tú también al suelo. Boca abajo. Quieto. No te muevas.

Hassan: ¿Qué hemos hecho?

Policía: Silencio.

La película no sigue un orden lineal. Por esta razón, el diálogo siguiente iría unido al anterior en el tiempo pero aparece algunos minutos después en la película, ya que se entrecruza con las otras tres historias. Sin embargo, la situación es la misma, ya que el policía y Hassan continúan en el C4:

Policía: ¿Por qué disparaste al autobús?

Hassan: Yo no disparé a nadie.

Policía: ¿Quién ha sido?

Hassan: No fui yo.

(El policía le pega un puñetazo)

Policía: El fusil es tuyo. No mientas.

Hassan: Ese fusil lo vendí ayer.

Policía: ¿Ayer? ¿A quién?

El último ejemplo puede encontrarse en una conversación entre Richard y Susan. Ella sufre por la infección y la fiebre y se acuerda de sus hijos. Lo que no saben ninguno de los dos, ni los espectadores, es que los niños estarán en peligro:

Susan: Quiero hablar con los niños. Richard, quiero hablar con los niños.

Richard: Sí, ya lo sé. Pero ahora no nos podemos mover.

Susan: Quiero hablar con los niños.

Richard: Cálmate.

Susan: Tengo que hablar con ellos.

Richard: Lo sé.

Susan: Tengo que hablar con los niños.

Abuela de Anwar: (Ofrece a Susan su pipa) Dele un par de caladas.

(Susan aspira y ella y Richard lloran. La anciana reza)

En esta conversación se localiza también un adaptador de objetos. Susan toma la pipa y la mano de la anciana como una especie de salvavidas. Calma su nerviosismo y deja de pensar en sus hijos, para relajarse por unos instantes.

\section{PIRÁMIDE DE NECESIDADES DE ABRAHAM MASLOW}

En este apartado se analizará cómo están presentes todas las necesidades enumeradas por Maslow, desde la base de su pirámide.

FISIOLÓGICAS: El mejor ejemplo se encuentra en el pasaje en el que Amelia y los niños están perdidos en el desierto, en alguna parte entre México y Estados Unidos. 
Hace mucho calor, llevan muchas horas sin dormir y no tienen bebida, ni comida. Por ello, su organismo sufre daños importantes. Debbie se desmaya y está deshidratada. Amelia, la única adulta, pierde la orientación y el sentido del tiempo.

DE SEGURIDAD: Los turistas que acompañan a Richard y Susan en el autobús sienten esta necesidad cuando son llevados a una aldea marroquí. Uno de ellos dice que están en peligro, ya que puede haber terroristas. Argumenta que en un pueblo similar de Egipto mataron a tres decenas de turistas alemanes. Se sienten amenazados en un territorio desconocido que les resulta hostil y quieren irse sin llevarse a la herida. Mientras, Richard siente necesidad de seguridad para su esposa, frente a la enfermedad y a la muerte. No le importa estar en medio del desierto marroquí porque tiene que esperar a la ambulancia y no puede mover a Susan.

SOCIALES: Chieko, la adolescente japonesa muestra esta necesidad en varias ocasiones. Necesita ser amada y formar parte de la sociedad, porque su minusvalía la deja fuera. Tiene seguridad, porque su padre es rico y viven en una buena casa, estudia en un buen colegio, va bien vestida y tiene todo tipo de aparatos de última tecnología (como su teléfono móvil con vídeo-llamada). Sin embargo, le falta asociarse a un grupo y tiene miedo a quedarse sola toda la vida.

En el partido de voleibol muestra esta necesidad. El árbitro determina que un pase suyo ha caído fuera y da el punto al equipo contrario. Chieko se enfada porque sabe que el tiro ha sido válido y dice con señas: "Soy muda, no ciega". Cree que no la toman en serio por ser sordomuda y finalmente, el árbitro la expulsa. Ella, encolerizada, le hace un corte de mangas porque es su única forma de defenderse ante los demás.

Además, quiere que los chicos la miren como a una chica normal. Para ello, se le ocurre quitarse las bragas y abrir las piernas ante la mirada de los jóvenes de otra mesa. Así se lo confiesa a su amiga en los lavabos del J-Pop:

Amiga de Chieko: ¿Qué estás haciendo?

Chieko: Ahora van a conocer al verdadero monstruo peludo.

(Se quita las bragas para abrir las piernas, mientras el chico la mira)

DE ESTIMA: Yussef es el mediano y quiere que su padre reconozca que es mejor tirador que su hermano mayor, Ahmed, el favorito de su progenitor. Se enfada porque le dejan en segundo lugar para probar el rifle. Sin embargo, luego lo coge con su hermano y dice que va a dar al autobús, porque quiere demostrar que tiene más puntería.

Este personaje necesita una caricia por parte de su padre, algo que Eric Berne definió como "la unidad básica de interacción social". Como Yussef no ha cubierto su necesidad de estima, tiene desdibujada su identidad. Es el hijo mediano y no está en ninguna parte: a Ahmed le quieren por ser el mayor y a Zorah la estiman por ser la única niña. Así que se refugia en su calidad como tirador y crea una autocaricia positiva. 
DE CONOCIMIENTO: Chieko también tiene necesidades de este tipo. Quiere explorar y conocer el mundo. No puede oír ni hablar, pero intenta sentir los estímulos que están cerca. Para ello, no duda en probar una pastilla con whisky. Cuando la droga ha hecho su efecto, danza con sus amigas entre las fuentes de la calle, pasea por un centro comercial y entra en una discoteca, donde ve las luces pero no oye la música estridente. Sin embargo, la droga hace que pueda bailar como cualquier otra chica normal.

Más adelante, su amiga le traiciona y se besa con el chico que deseaba Chieko. Enfadada, sale de la discoteca y en el camino hacia su casa, ve un grupo de rock ensayando en un escaparate. No puede oírles, pero se detiene durante unos segundos para observarles detenidamente e imaginar cómo suena su música.

ESTÉTICAS: Susan es una mujer norteamericana con dinero. Tiene dos hijos, una bonita casa y viaja a Marruecos muy bien vestida. Necesita orden y belleza en su vida y en su aspecto. Por ello, no prueba la comida marroquí, tira los hielos del refresco y se limpia las manos con una crema anti-bacterias. Sin embargo, cuando le alcanza la bala y está herida, olvida esta necesidad estética. Deja que la tumben sobre una alfombra vieja y permite a un veterinario que cosa su herida con una gran aguja usada para curar animales.

DE AUTORREALIZACIÓN: Normalmente, esta necesidad es propia de aquellas personas con valores elevados y una identidad muy bien dibujada. Tienen todas las necesidades anteriores cubiertas, por lo que buscan una satisfacción superior. El único personaje que podría acercarse a esta necesidad es Richard. Tiene un buen trabajo, una gran casa, una familia, dos hijos a los que quiere, es guapo y está muy bien integrado en la sociedad. Sólo le falta ganarse el perdón de su esposa y ser un buen padre, ya que huyó después de la muerte de su hijo Sam. Siente que es un cobarde y no ha hecho bien su tarea. Pero quiere una segunda oportunidad para realizarse como padre y marido:

Richard: Perdóname, mi amor. Cuando murió Sammy, no... Huí. Tuve miedo.

Susan: Yo también lo tuve.

Richard: Lo sé.

Susan: Fue por mi culpa.

Richard: No, no fue culpa tuya. Me equivoqué. Te quiero muchísimo. Ya no recuerdo su cara.

\section{CONDUCTA NO VERBAL}

EMBLEMAS: Los mejores emblemas de la película son el lenguaje de signos de Chieko y su amiga. La primera es sordomuda y la segunda sólo es sorda, ya que puede pronunciar algunas palabras. Se llevan muy bien y para comunicarse, utilizan ese lenguaje lleno de emblemas.

Son actos no verbales con traducción verbal directa. Pero en su caso no se usan por ruido o distancia, sino por una circunstancia física insalvable. 
También hay emblemas en los gestos del árbitro de voleibol. Gracias a ellos, comunica que el saque es válido, que Chieko ha cometido una falta y a continuación, que está expulsada y debe abandonar el partido.

ILUSTRADORES: El mejor ejemplo de la película se encuentra en la escena de la frontera entre México y Estados Unidos. El agente ordena a Santiago que salga del vehículo y añade información a este mensaje, al desenfundar su arma y poner la mano sobre ella. Con este ilustrador quiere transmitir que está hablando muy en serio y de forma amenazante; no va a dudar en disparar si es necesario.

ADAPTADORES: Cuando Amelia es interrogada por el agente de aduanas, se frota las manos de forma compulsiva y da vueltas con los dedos sin parar. Con este adaptador, el espectador puede reconocer su nerviosismo. $Y$ al mismo tiempo, el personaje intenta mantenerse íntegro ante el policía, en un momento tan complicado.

Chieko también emplea muchos adaptadores. Al "hablar" con el chico que le gusta, se muestra nerviosa y se toca el flequillo en varias ocasiones. Por otra parte, cuando habla con el policía por el que se siente atraída, se ayuda de un adaptador de objetos: su libreta, en la que anota todo lo que quiere decir.

Sin embargo, Susan es el personaje que recurre a más adaptadores. Cuando está comiendo en el chiringuito marroquí con su marido, se unta crema anti-bacterias en las manos y se frota los dedos una y otra vez. Su objetivo es intentar controlarse para no discutir con Richard inmediatamente.

Después, en el autobús, intenta dormir una pequeña siesta antes de ser alcanzada por la bala perdida. Ahí toma la mano de Richard de repente y la estrecha. El mensaje que quiere transmitir es que volverán a intentarlo y ella tratará de perdonarle.

El último ejemplo, y más dramático, llega cuando Susan está herida, tumbada en casa de Anwar. Sufre mucho dolor y la anciana le ofrece una pipa, que ella utiliza como adaptador de objetos para calmar su malestar.

\section{FASES DE LA NEGOCIACIÓN}

INFORMACIÓN: En esta fase se pretende recopilar datos, identificar objetivos y necesidades. En el diálogo recogido anteriormente, entre Santiago y el agente de aduana hay un buen ejemplo. El agente no para de hacer preguntas cerradas con el fin de poner nervioso a Santiago y ver cómo puede pillarle:

- “¿De dónde vienen?"

- "¿De dónde son?"

- “¿Adónde se dirigen?"

- “¿Quiénes son?”

- “¿Tiene sus pasaportes?"

- “¿Está usted a cargo de ellos?” 
- “¿Esta señora es tu tía?”

- “¿Está bajo los efectos de alcohol?"

En Marruecos, se pueden encontrar otro tipo de interpelaciones. Los turistas acosan a Richard con preguntas de situación y preguntas sobre problemas. Quieren saber cómo está Susan sólo para poder marcharse:

- “¿Cómo está su mujer?"

- “¿Cómo está su esposa?"

- “¿Por qué tenemos que quedarnos?"

Igualmente, en el interrogatorio a Amelia, se pueden encontrar preguntas de confrontación y respuestas arrogantes y punzantes por parte del agente:

- Policía de inmigración: ¿Sabe cuántos niños mueren cada año intentando cruzar esta frontera?

- Policía de inmigración: Pero no son sus hijos, señora. Además, está trabajando en el país de manera ilegal.

- Amelia: ¿Qué sabe de mi sobrino Santiago?

- Policía de inmigración: No dispongo de esa información. Hemos localizado a su padre en Marruecos. Se enfadó mucho pero no la denunciará.

- Policía de inmigración: Eso debió pensarlo antes, señora.

- Policía de inmigración: Si lleva este asunto a juicio, le puedo asegurar que sólo estará prolongando lo inevitable. Le recomiendo que acepte la deportación voluntaria.

PERSUASIÓN: Después de recopilar toda la información, llega esta fase. Las motivaciones son el eje principal y en Babel se pueden reconocer los tres tipos:

1. Motivación positiva directa: Anwar, el guía, intenta esperanzar a Richard. Le dice que su casa está cerca y que en su aldea hay un médico que atenderá a Susan. Ve la gravedad de la situación y sabe que el americano necesita ayuda y apoyo para mantener la calma.

2. Motivación positiva indirecta: El representante diplomático negocia con Richard por teléfono. No llegará ninguna ambulancia, pero promete un helicóptero. El interlocutor está nervioso e intenta calmarle, crear un buen clima. Por ello le tranquiliza con un tono de voz frío y pausado y estas palabras: "Hago todo lo que puedo".

Yasujiro también intenta crear un buen clima con su hija. Quiere hablar con ella y se mantiene tranquilo, amable, sereno. Nunca sube el tono de voz y si su hija intenta iniciar una discusión, él la calma con gestos de cariño.

3. Motivación negativa o disuasión: El agente de la aduana intenta disuadir a Santiago con el gesto de desenfundar su arma. Es la manera de mostrar que está en una posición de poder superior, que tiene el mando y el mexicano debe obedecerle.

INSTRUCCIÓN: En esta fase se estudiarán las técnicas de presión que aparecen en la película: 


\section{Adición:}

Participación: Esta técnica apela a las necesidades de pertenencia a un grupo. La emplea el grupo de turistas cuando argumentan que deben irse porque están en peligro y Richard debe acompañarles porque es arriesgado quedarse en ese lugar.

Planchado: Cuando Richard habla con sus compañeros de viaje, señala desde el principio que no se moverá hasta que Susan mejore o venga una ambulancia a por ella. También emplea esta técnica en la conversación telefónica con el diplomático, ya que desde el principio dice que quiere una ambulancia cuanto antes.

\section{Tácticas de sustracción:}

Límites temporales y espaciales: El ejemplo más claro vuelve a darlo uno de los turistas norteamericanos que acompañan a Richard y a Susan. Impone un límite temporal en la negociación, treinta minutos:

Turista 2: Hay gente que no está en condiciones de esperar. ¿No lo entiende?

Richard: Por favor, esperen. La ambulancia no tardará en llegar. Sólo unos minutos.

Guía marroquí: Por favor, les ruego que esperen.

Turista 2: Treinta minutos. Le damos treinta minutos.

Silencio e inmovilidad: Susan utiliza esta técnica con Richard para mostrar su enfado. Cuando van a comer en el chiringuito, ella apenas habla. Guarda silencio y no hace ningún gesto. Esto desconcierta a Richard, que no sabe cómo pedirle perdón. Ella tiene la iniciativa y el poder en la relación. Fue la esposa abandonada pero el futuro del matrimonio está ahora en su mano.

Paciencia: Yasujiro recurre a controlar el tiempo con su hija, Chieko. Es prudente con sus palabras, acciones y silencios. Deja espacio para que su hija manifieste sus inquietudes y cuando es el momento oportuno, expresa sus peticiones. Su paciencia dura ya nueve meses, el tiempo que ha transcurrido desde el suicidio de su esposa. Pero al final gana y su hija vuelve a él, pidiéndole perdón por tanto dolor con un abrazo.

\section{Tácticas de sustitución:}

Sorpresa: Uno de los turistas pregunta a Richard por Susan. Intenta mostrarse condescendiente para ganarse la confianza del otro y preparar el terreno para convencerle de que deben marcharse. Sin embargo, de repente cambia su discurso y dice abiertamente que deben irse ya:

Turista 2: Se está haciendo de noche. Hay gente que no se encuentra bien. Es peligroso. ¡A la mierda! ¡Nos vamos!

Cuando se emplea esta técnica, el negociador intenta demostrar que tiene el poder y la iniciativa. El resultado suele ser un movimiento en el interlocutor y Richard responde rápidamente: intenta dar un puñetazo al turista y le tira al suelo. 
Cambiar de tema: Chieko quiere ligar con el policía. Él está preguntando por su padre y por el fusil. De forma inesperada, ella cambia de tema y se pone a hablar del suicidio de su madre:

Chieko: (Escribe) Mi padre no tuvo nada que ver en la muerte de mi madre.

Policía: ¿A qué viene esto?

(Chieko escribe)

Policía: Entonces, cuando su madre se tiró por el balcón, ¿su padre dormía?

(Chieko asiente y salen al balcón. Chieko escribe)

Policía: ¿La vio usted saltar?

(Chieko asiente)

Policía: ¿Se lo ha dicho a los otros agentes?

(Chieko asiente)

Policía: ¿Se puede saber qué intenta decirme?

\section{CONCLUSIONES}

En los Premios de los Oscar de marzo de 2006, Infiltrados, de Martin Scorsese, robó la estatuilla de Mejor Película a Babel. Quizá no era la mejor película del experimentado director neoyorquino, pero era un reconocimiento necesario y esperado. La parte triste se la llevó Alejandro González Iñárritu. Su tercera película estaba en muchas quinielas, aunque tendrá que esperar otra oportunidad. Este hecho no quita brillo a su último trabajo, analizado en las páginas anteriores. Lejos de su preciosismo o calidad cinematográfica, Babel es una obra profunda, muy meditada y comedida. En dos horas y cuarto, sólo hay un guión de 20 o 30 páginas. Resulta sorprendente que tan pocas palabras puedan encerrar tanto contenido comunicativo.

Las cuatro historias se entrelazan sabiamente. Un crítico de cine resaltaría que cada una de ellas tiene un color, una textura y una música diferentes. Sin embargo, aquí interesa unificar en lugar de excluir. Se puede afirmar que en los cuatro escenarios y en los cuatro cuentos hay un denominador común mayor que cualquier técnica de cámara: la incomunicación. Eso intenta transmitir el director y precisamente, debería ser remarcado por los críticos que sólo resaltaron el montaje o las localizaciones.

Además, ese mensaje utiliza un código muy bello: el de la mesura. Dice muchas cosas con muy pocas palabras. No hay una escena con diálogo sin sentido, juego o negociación. Todos los personajes son definidos a la perfección. El espectador puede conocer su pasado, sus tragedias, la forma en que afrontan el presente y el miedo que tienen al futuro. González Iñárritu utiliza la retórica de Aristóteles, habla de todas las necesidades humanas que enumeró Maslow y muestra unos juegos comunicativos muy variados. El objetivo es mostrar el dolor que puede causar lo que no se dice, un problema universal que hace necesario viajar por tres continentes distintos.

Durante la película, el espectador podrá ver también cómo la comunicación cambia a las personas. Susan se perdona a sí misma de la muerte de su hijo y a la vez, perdona a su marido y le devuelve el permiso para amar. Richard asume su error y sus miedos y da a Susan permiso para vivir, porque ya no puede perderla otra vez. 
Amelia ve que un error puede cambiar una vida en un instante y pierde su permiso para trabajar. Chieko consigue madurar y aceptar la muerte de su madre y su minusvalía para seguir viviendo. Todos estos cambios de $180^{\circ}$ son fruto del azar, de una bala perdida disparada por dos niños marroquíes que aún no saben mucho de la vida.

Todo ello deberá ser descubierto por el público, que puede verse reflejado en Babel. Esa es la grandeza de las grandes historias. No importan los escenarios o la raza de los protagonistas, si el ser humano y su forma de comunicarse con los demás quedan tan bien descritos como en este caso.

\section{BIBLIOGRAFÍA}

Berne, E. (2007): Juegos en que participamos. Barcelona: RBA Integral.

Valbuena, F. (2006a): Eric Berne. Teórico de la Comunicación. Madrid: Edipo.

Valbuena, F. (2006b). Análisis de la película Esencia de mujer (1992), en Revista de Análisis Transaccional y Psicología Humanista, nº 60, p. 17-21.

Valbuena, F. (2007a). Análisis de la película Hotel Rwanda (2004), en Revista de Análisis Transaccional y Psicología Humanista, no 61, p. 71-79.

Valbuena, F. (2007b). Análisis de la película La vida de los otros (Desde el Análisis Transaccional y la Teoría de la Negociación), en Cuadernos de Información y Comunicación, oㅜ 12, p. 119-135. 